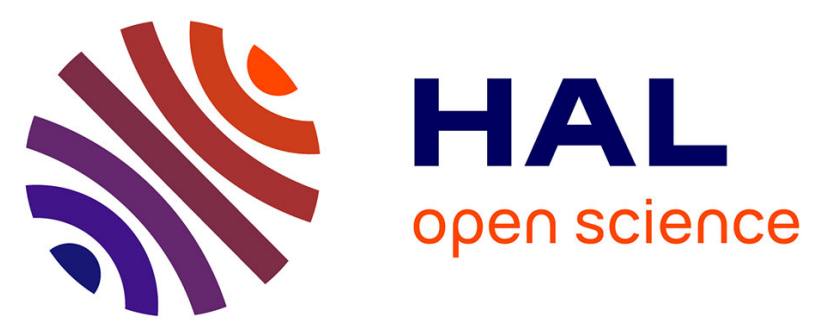

\title{
Child's Play - A Literature-Based Survey on Gamified Tools and Methods for Fostering Public Participation in Urban Planning
}

Kevin Klamert, Sander Münster

\section{- To cite this version:}

Kevin Klamert, Sander Münster. Child's Play - A Literature-Based Survey on Gamified Tools and Methods for Fostering Public Participation in Urban Planning. 9th International Conference on Electronic Participation (ePart), Sep 2017, St. Petersburg, Russia. pp.24-33, 10.1007/978-3-31964322-9_3. hal-01703324

\section{HAL Id: hal-01703324 \\ https://hal.inria.fr/hal-01703324}

Submitted on 7 Feb 2018

HAL is a multi-disciplinary open access archive for the deposit and dissemination of scientific research documents, whether they are published or not. The documents may come from teaching and research institutions in France or abroad, or from public or private research centers.
L'archive ouverte pluridisciplinaire HAL, est destinée au dépôt et à la diffusion de documents scientifiques de niveau recherche, publiés ou non, émanant des établissements d'enseignement et de recherche français ou étrangers, des laboratoires publics ou privés. 


\title{
Child's play - A literature-based survey on gamified tools and methods for fostering public participation in urban planning
}

\author{
Kevin Klamert, Sander Münster \\ Media Center, Technische Universität Dresden, D-01062 Dresden, Germany \\ kevin.klamert@tu-dresden.de, sander.muenster@tu-dresden.de
}

\begin{abstract}
As urban planning processes are often complex and protracted, fostering public participation in this sector has to be seen as a major challenge. Nevertheless, previous research on that topic offers various solutions that aim to tackle that problem, either by focusing on playful formats or on gamification and serious gaming. Often examined separately, these approaches deliver promising strengths to improve public participation in the urban sphere. Hence, a synopsis of those strategies seems to be worthwhile and is therefore further investigated in this paper. In order to analyze current works on that issue systematically, the paper is structured via a literature-based classification of different stages of public participation that distinguish whether citizens are being informed, consulted or collaborated with during the planning process. By giving an insight on innovative participation tools and methods in this field, the pursued outcome of this article are impulses for designing an advanced participatory platform which is part of the research project U_CODE (Urban Collective Design Environment).
\end{abstract}

Keywords. public participation, urban planning, mobile participation, gamification, playfulness, serious gaming, augmented reality

\section{Introduction}

At first glance, fostering a citizen's interest in the field of urban planning seems to be challenging. But, due to the technological progress and innovative research approaches, the field is actually given a wide range of possibilities for increasing civic engagement and effectively tackling signs of political apathy. Imagine a smartphone app that demands users to explore neighborhoods in order to find nearby planning projects: After receiving a GPS-based notification, the person uses their smartphone for displaying first design proposals of the future building right at the spot. The user also receives additional information about the project which automatically pops up on the screen. Additionally, the person gets the possibility to comment, rate and share the project proposal and is able to answer project-related requests for feedback. By doing so, every single user action is tracked by a gamified design that not only incorporates user input in the decision-making process but also stimulates engagement, rewarding dedicated users with invitations to collaboratively work with involved professionals.

That single sequence demonstrates only one of (possibly) many ideas for increasing public participation in urban planning. Starting with this example, the intention of this paper is to evaluate how public participation can be designed in an exciting way for efficiently raising civic engagement and, ultimately, improving mutually accepted decisions in the field of urban planning. It approaches this question 
by investigating new technologies as well as recent scientific knowledge. Based on literature concerning different stages of public participation, the goal of this paper is to deliver a systematic overview of recent developments that distinguish between the levels of citizen influence in the process of public participation.

One of the major hurdles for participative planning processes we investigated in another study [1] is that especially publically initialized participative activities often lack a sufficient number of users. This may be caused by lacking information on the process [e.g. 2, 3], barriers in culture, understanding or accessibility [e.g. 4] or even weak motivation to participate [e.g. 5]. Therefore, motivational strategies such as gamification as well as the implementation of playful approaches through innovative technologies are in the scope of this investigation, each of them providing valuable impressions for designing a well performing prototype of a participatory system which is the goal of the U_CODE (Urban Collective Design Environment) research project.

\section{Gamification, playfulness and mobile participation}

Game and play open innovative ways for making public participation more exciting, which is why research in this field serves as a theoretical framework of this paper. As shown in the introductory scenario, formats of mobile participation are an important aspect of this work, too, as they expand the range of possibilities for the implementation of gamification or playfulness in matters of urban planning as well as being promising to overcome the mentioned obstacles. Mobile participation "covers all initiatives, actions and methods that result from mobile end devices (e.g. mobile phones, smartphones and tablets) via wireless communication technology in order to expand the participation of citizens and other stakeholders in urban planning processes" [6]. Because mobile enabled tools can be used everywhere and anytime, the participation process no longer depends on time and space. Also, the mobile participation approach increases the chance to reach an audience who is normally missing in the participation process [7].

When it comes to motivating people to engage in public affairs, the research area on gamification offers solutions. In literature, several understandings of the term exist (for an overview [8,9]). A widely accepted definition of gamification describes it as the "use of game design elements in non-game contexts" [10]. Zichermann and Cunningham focus on gamification as "the process of game-thinking and game mechanics to engage users and solve problems" [11]. Gamification is "usually intended to create gameful and playful user experiences, motivate desired user behaviors, and generally, increase joy of use" [12]. So, it can be stated that the goal of gamification is to engage users to take desired actions and to solve real-world problems - by using game elements. In the case of urban planning, solving real-world problems would mean tackling the deficit of participation that normally requires citizens to engage for a long period of time in order to give a constant input to a generally tedious decision-making process. Well-known game elements are e.g. point systems, badges or leaderboards, progress bars and quests. The diversity in understanding gamification makes it difficult to compare findings, and recent studies on the motivational impact of gamification elements partly lack scientific accuracy [9]. Yet, positive effects of gamification on user behavior are attested $[13,14]$. 
Deterding et al. distinguish gamification from two other aspects: playful design that in contrast to gamification contains no rules or specific goals, and serious games that are rather defined as full-fledged games for non-entertainment purposes [10]. But clearly allocating a format in either gamification, playful design or serious gaming sometimes can be difficult and is not the intention of this paper. In order to present lines of development on promising public participation formats, it seems rather beneficial to not only explore gamification in the field of urban planning but also to include approaches that more likely refer to the field of playfulness or serious games. Following the idea of immersive planning, diverse ways should be able to bring citizens into an experience during the public participation process, e.g. by using 3D environments or by GIS-based technologies [15]. In terms of public participation, settings that are generally considered to be inefficient such as forms of play do not have to be at a disadvantage but can instead facilitate the evolvement of meaningful civic actions [16].

\section{Methodology}

Since there was recently much research on gamification for both conceptual and practical implementation, the methodical approach was to review and classify that literature. From a methodical point of view, a literature review is "a systematic search of published work to find out what is already known about the intended research topic" [17], to provide "an informed evaluation of that literature" [18]. A literature review is a relatively low standardized method and relies on stages of data search and critical evaluation [19]. Since this investigation provides a basis for a future development of a gamified platform for citizen engagement in urban planning, a purpose of this study is to "familiarize the researcher with the latest developments in the area of research" and „study the definitions used in previous works as well as the characteristics of the populations investigated, with the aim of adopting them for the new research" [20]. Therefore, the outcome of this paper is a descriptive and structured overview of recent gamified or playful participation tools that can be used for urban planning processes.

In order to retrieve information on that subject, a literature review on innovative public participation formats especially in the field of urban planning was performed. It focused on the aspects of gamification, playfulness and mobile participation, using the search items "gamification", "gamif*”, "playful”, "mobile participation" and "urban planning", including the databases EBSCOHost, ACM Digital Library and Scopus. Besides, by using the snowball principle, additional scientific works were found that were not covered by the database-driven keyword search. Due to the rapid development in this research field, an additional internet research went beyond scientific contributions and included current participation services in urban planning. In total 188 publications were retrieved and assessed.

The final selection of the findings was based on whether the participation tool exemplarily represents a new facet to the topic of public participation in urban planning. As such, it can not only represent characteristics of gamification but also of playfulness or serious gaming. By uncovering the diversity of tools and methods that are currently available, the obtained results present an overview of the state of the art and offer impulses for shaping the future design of an innovative and well performing participation system. 
Table 1. Stages of citizen participation

\begin{tabular}{llll}
\hline Category & Information & Consultation & Collaboration \\
\hline Description & Citizens inform themselves & Citizens are asked to & Citizens and other \\
& or are being informed of & give input and feedback & stakeholders actively work \\
& current plans, decisions and & (e.g. opinions, solutions) & together in decision- \\
& actions & & making
\end{tabular}

For clustering the results of this investigation, literature on public participation provides a categorization that distinguishes different stages of public influence on final decisions. Most commonly, actively sharing information with the public or giving them the possibility to inform themselves is declared as a first step of citizen participation [21-24]. On this informational level, citizens usually are not able to reply to the professional's input, which is why it is described as one-way communication [21] or one-way relationship [23]. A broader form of public participation is achieved when the public is consulted in an urban planning process, which means that public feedback is collected and taken into consideration in the decision-making [22]. However, at this stage, it still depends on the planner's decision whether to include that feedback. In contrast, a farther-reaching dimension of participation named collaboration stresses a partnership between the public and the planners in which citizen's advice is being implemented "to the maximum extent possible" [22]. On that stage, citizens directly contribute to the process of urban planning by discussing ideas, developing solutions and creating alternatives in deep interaction with other stakeholders.

Despite the fact that literature mentions even higher stages of public participation, the following structure is considered to be best suitable for classifying participation tools and methods for the purpose of this paper (Table 1).

\section{Results}

\subsection{Information}

When it comes to informing the public in urban planning processes, visualization techniques such as augmented reality (AR) offer a variety of innovative solutions to effectively support informational purposes. For instance, mobile devices can be used in order to display designs of urban planning projects in existing landscapes [6, 25]. By that, citizens can playfully evaluate a proposal from different perspectives and are able to explore the planner's intention at an early stage of a project. This approach can be carried forward, allowing users to edit 3D visualizations or to vote for favored project proposals [26], which would of course go beyond the stage of public informing. With AR technology, transforming a 2D development plan into 3D for a better understanding among non-professionals or improving ordinary city walks by displaying additional information of buildings is also possible [27]. In addition, environment-centric applications which are often initiated by local governments such as "Metropulse" enable a one-way flow of information from those responsible to the citizens [28]. An example for visualizing future districts and allowing users to virtually explore future public places illustrates the 3D app "Dundee Waterfront 2018” [29].

Moreover, virtual worlds such as the online platform "Second Life" offer playful environments in which citizens can familiarize themselves with urban issues, exploring 
future public spaces by controlling an avatar [30]. This kind of immersive experience shows potential to inspire people to engage in urban planning projects. The approach can easily be gamified, e.g. by implementing tasks and high scores into the design. Besides informing citizens, it would also be possible to request public feedback for urban planning projects: In the case of the tool "Participatory Chinatown", it can even form a coherent game [15] that facilitates a process of deliberation among stakeholders.

\subsection{Consultation}

In terms of consulting the public in matters of urban planning, the online platform "Nextsuisse" gathers concepts on the future of Switzerland by asking users to propose text-based ideas and to play a web-based scenario game. Participants can playfully create 2D scenarios of their hometown by placing urban elements such as houses, trees and shopping malls on a virtual city framework. Adding elements to the setting influences the displayed overall satisfaction level of the city, and doing so in a sustainable way is being rewarded with positive feedback [31]. In that way, the citizen gets a feeling for the needs of their hometown. The created scenarios are published on the platform and can there be viewed and rated by others. Beyond consultation, the platform also arranges real-life collaborative workshops.

Other consulting formats focus on citizens as local experts and strive to collect neighborhood knowledge by using mobile data collection tools. For instance, the mobile application "Maplocal" asks users for feedback about their residential environment by letting them post photos or commentaries. The design seeks to improve public engagement in the early phase of planning processes [32] and offers playful options to contribute to the planning process by simply wandering around a familiar district. Moreover, valuable data for planners can be aggregated passively by mobile apps [6]: "Stereopublic" and "Widenoise" capture noise levels and display them on a map [33]. By identifying silent and noisy areas in cities, those apps deliver useful input for the urban planner's decision-making. Moreover, these environmental monitoring formats can be gamified [34] for improving the user's motivation to contribute.

The online platform "MetroQuest", whose design is inspired by a game called "Sim City", educates the public about urban projects through a series of informative screens and offers options to rank priorities, rate scenarios or allocate budgets, whereas professionals can use the platform e.g. by initiating surveys. By offering a variety of screen-based participation formats, the tool is adaptable for many urban planning projects, supporting options for different levels of civic engagement. Similar to "MetroQuest", the data-based platform "mySidewalk", formerly known as "MindMixer", allows civic decision makers to engage with their residents by letting citizens post ideas, give feedback or support and vote on urban planning ideas. The platform uses a gamified design that rewards user activities with digital coins and also implements high score lists for raising user motivation [31].

\subsection{Collaboration}

Initiating an intense process of collaboration between the public and professionals is the intention of a gamified mobile app called "Community Circles". It stimulates user interactions and contributions that refer to local urban planning issues with digital points [31]. Similar to "Maplocal", the app demands participants to explore their location in order to participate. Additionally, in-app crowd-sourced user contributions 
will gradually disappear from screen after a certain period if community feedback is lacking - in that way, high amounts of user input is managed. The platform not only allows citizens to contribute opinions and ideas, but also offers city authorities the chance to give constructive feedback or to raise urban issues [35]. By initiating intense interaction, this design approach aims to facilitate a mutual collaboration process between users and the local government [36].

The mobile participation tool "Love your City" takes a similar approach such as "Community Circles", seeking intense collaboration among all stakeholders in the urban planning process, but it thereby focusses on AR visualization technology. By introducing an AR-based interface that accomplishes participation activities between users and local governments at a user's current location, the tool aims to facilitate cocreation processes between stakeholders [37]. Depending on the situation and complexity of tasks, either citizens or city administrations can perform actions within the participation process, starting with the initiation of an issue, leading to a stage of co-creating and decision-making and finally ending in the display of visible results. User actions are rewarded with points and are tracked within a user profile [38].

Finally, the web-based online platform "Community PlanIt" is designed for assisting urban planning meetings, transforming an urban instance into a "mission" that contains game elements such as challenges, leaderboards and in-game rewards. By completing those missions, the citizen contributes to the planning process, earning virtual coins which can be spent to support urban concepts that frame the topic [31]. Additionally, the platform seeks to integrate as many stakeholders as possible and strives to initiate a mutual learning process. Besides online activities, the game final is facilitated by an offline workshop that is also open for non-members [39]. Similar to "Community PlanIt", the platform "Play the City" creates game scenarios that engage multiple stakeholders to meet physically and to collaboratively resolve complex urban challenges.

\section{Conclusions}

Considering the stages of the public participation process, the findings of this paper reveal a diversity of approaches in the field of urban planning, each offering impulses for creating a sustainable system for public participation.

First of all, the growing number of mobile devices in use obviously lowers barriers for participation and raises the chance for addressing a wider range of participants. In matters of urban planning, mobile tools can playfully facilitate the collection of public feedback as well as the communication between citizens and experts. Moreover, they allow displaying urban design proposals right at the spot, which might foster interest in public participation. The findings also reveal that urban planning projects can even be designed as full-fledged games in which citizens interact with other stakeholders in a playful manner. Furthermore, gamification strategies show potential not only to arouse curiosity for participation formats but also to improve long-term user motivation to participate. Commenting and rating design proposals, sharing own ideas or playing goal-related project missions can be rewarded with points or badges, while formats of discovery motivate people to explore their district in order to find urban issues of public interest.

Conceptualizing a platform that facilitates participation in every stage of the urban planning process is challenging. A gamified crowdsourcing service that effectively 
collects contributions and ensures in-depth communication and feedback at an early stage covers only one aspect of the process. At later stages, visualization techniques such as 3D environments and augmented reality sketches of future buildings show potential to make urban projects more exciting and tangible. For this, the concept of "Metropulse" provides a solution as it offers a toolbox of participation formats that are adaptable for every stage of a project. Following this approach, different levels of citizen involvement during the urban planning process can be considered, having a flexibility to offer several participation modules a project owner is willing to accept. But in order to foster intense collaboration processes, the examples of "Community PlanIt" and "Nextsuisse" advise that online technologies cannot replace the necessity of real-world meetings that include all stakeholders, which is why real-world workshops also remain important for the process.

Since participation processes as well as related challenges have been in focus of research for long [cf. 1], the employment of gamification strategies and principles within these contexts would add novel opportunities as well as raise novel questions for future investigations. To provide two examples: As figured out in many studies, people willing to participate in urban planning processes rarely represent a majority of inhabitants or involve (potential) opinion leaders [e.g. 40, 41]. A related question would be whether gamified approaches could help to overcome these challenges, e.g. by motivating these opinion leaders to actively mobilize followers. Especially when using digital tools, the digital readiness, accessibility and communication channels have to be considered and thoroughly analyzed. It would be of interest to investigate if and how digitized and gamified approaches would maybe exclude stakeholder groups.

The results of this paper only give an introductory overview of the field of current participation formats in urban planning and have no claim to being complete. They are primarily used to provide impulses for the design of an advanced participation platform. However, to reasonably implement such tools and methods within an overall concept is challenging, which is why future research on how to effectively implement gamification into a participation environment as well as on how to coordinate innovative service modules into an overall design remains a major task of the project.

\section{Acknowledgements}

The research upon which this paper is based was part of the project U_CODE (Urban Collective Design Environment) which has received funding from the European Union's Horizon 2020 research and innovation program under grant agreement No 688873.

\section{References}

1. Münster, S., Georgi, C., Heijne, K., Klamert, K., Nönnig, J.R., Pump, M., Stelzle, B. (accepted paper). How to involve inhabitants in urban design planning? An overview on a state of the art, key challenges and promising approaches. KES 2017.

2. Brabham, D.C. (2009). Crowdsourcing the Public Participation Process for Planning Projects. Planning Theory 8, 242-262.

3. Nabatchi, T. (2012). A Manager's Guide to fostering Transparency and Democracy. IBM Center for The Business of Government. 
4. Deyle, R., Schively Slotterback, C. (2009) Group Learning in Participatory Planning Processes. Journal of Planning Education and Research 29, 23-38.

5. Giering, S. (2011). Public Participation Strategies for Transit. New York: Howard/Stein-Hudson Associates.

6. Höffken, S. (2015). Mobile Partizipation: Wie Bürger mit dem Smartphone Stadtplanung mitgestalten. Lemgo: Rohn.

7. Ertiö, T.-P. (2013). M-participation: the emergence of participatory planning applications: Research Briefings 6b.

8. Kim, B. (2015). Understanding Gamification. Library technology reports: v. 51, no. 2. Chicago, IL: American Library Association.

9. Seaborn, K., \& Fels, D. I. (2015). Gamification in theory and action: A survey. International Journal of Human-Computer Studies, 74, 14-31.

10. Deterding, S., Dixon, D., Khaled, R., \& Nacke, L. (2011). From Game Design Elements to Gamefulness: Defining “Gamification”. In Proceedings of the 15th International Academic MindTrek Conference Envisioning Future Media Environments (pp. 9-15). New York, NY: ACM.

11. Zichermann, G., \& Cunningham, C. (2011). Gamification by design: Implementing game mechanics in web and mobile apps. S.l.: O'Reilly.

12. Deterding, S., Björk, S., Nacke, L., Dixon, D., \& Lawley, E. (2013). Designing Gamification: Creating Gameful and Playful Experiences. In W. E. Mackay (Ed.), CHI '13 Extended Abstracts on Human Factors in Computing Systems (pp. 3263-3266). New York, NY: ACM.

13. Hamari, J., Koivisto, J., \& Sarsa, H. (2014). Does Gamification Work? - A Literature Review of Empirical Studies on Gamification. In 47th Annual Hawaii International Conference on System Sciences (pp. 3025-3034). Piscataway, NJ: IEEE.

14. Morschheuser, B., Hamari, J., \& Koivisto, J. (2016). Gamification in Crowdsourcing: A Review. In T. X. Bui \& R. H. Sprague (Eds.), Proceedings of the 49th Annual Hawaii International Conference on System Sciences (pp. 4375-4384). Piscataway, NJ: IEEE.

15. Gordon, E., Schirra, S., \& Hollander, J. (2011). Immersive Planning: A Conceptual Model for Designing Public Participation with New Technologies. Environment and Planning B: Planning and Design, 38(3), 505-519.

16. Gordon, E., \& Walter, S. (2016). Meaningful Inefficiencies: Resisting the Logic of Technological Efficiency in the Design of Civic Systems. In E. Gordon \& P. Mihailidis (Eds.), Civic media. Technology, design, practice (pp. 243-266). Cambridge, Massachusetts: The MIT Press.

17. Robinson, D. \& Reed, V. (1998). The A-Z of Social Research Jargon. London: Ashgate Publishing Limited.

18. Power, T. (2012). Guidelines for a Literature Survey and an Annotated Bibliography. http://www.trinity.utoronto.ca/library_archives/theological_resources/Theological_guid es/literature_survey_bibliography.html.

19. Bortz, J. \& Döring, N. (2009). Forschungsmethoden und Evaluation für Human- und Sozialwissenschaftler. Heidelberg: Springer-Medizin-Verlag.

20. Bless, C., \& Higson-Smith., C. (2000). Fundamentals of social research methods: an African perspective. Lusaka: Juta Education.

21. Arnstein, S. R. (1969). A Ladder of Citizen Participation. Journal of the American Institute of Planners, 35(4), 216-224.

22. IAP2. (2013). IAP2 public participation spectrum. Louisville. Retrieved from IAP2 website: 006 brochure a3 internat.pdf

23. OECD. (2001). Citizens as Partners: OECD Handbook on Information, Consultation and Public Participation in Policy-Making. Paris: OECD Publishing.

24. Tufte, T., \& Mefalopulos, P. (2009). Participatory Communication: The World Bank

25. Broschart, D., \& Zeile, P. (2014). Augmented Reality in Architektur und Stadtplanung - Techniken und Einsatzfelder. In J. Strobl, T. Blaschke, G. Griesebner, \& B. Zagel (Eds.), Angewandte Geoinformatik 2014. Beiträge zum 26. AGIT-Symposium Salzburg (pp. 638-647). Berlin: Wichmann.

26. Gnat, M., Leszek, K., \& Olszewski, R. (2016). The Use of Geoinformation Technology, Augmented Reality and Gamification in the Urban Modeling Process. In O. Gervasi, B. Murgante, S. Misra, A. M A. Rocha, C. M. Torre, D. Taniar, S. Wang (Eds.), Lecture Notes in Computer Science. Computational Science and Its Applications - ICCSA 2016 (pp. 484-496). Cham: Springer International Publishing.

27. Broschart, D., \& Zeile, P. (2015). ARchitecture: Augmented Reality in Architecture and Urban Planning. In E. Buhmann (Ed.), Peer reviewed proceedings of digital landscape architecture 2015 at Anhalt University of Applied Sciences (pp. 111-118). Berlin: Wichmann. 
28. Ertiö, T.-P. (2015). Participatory Apps for Urban Planning - Space for Improvement. Planning Practice \& Research, 30(3), 303-321.

29. Evans-Cowley, J. (2016). The Best Planning Apps for 2016. Retrieved from http://www.planetizen.com/node/82996/best-planning-apps-2016

30. Mallan, K., Foth, M., Greenaway, R., \& Young, G. T. (2010). Serious playground: Using Second Life to engage high school students in urban planning. Learning, Media and Technology, 35(2), $203-225$.

31. Thiel, S.-K., \& Lehner, U. (2015). Exploring the effects of game elements in m-participation. In S. Lawson \& P. Dickinson (Eds.), Proceedings of the 2015 British HCI Conference (pp. 65-73). New York, NY: ACM.

32. Jones, P., Layarad, A., Speed, C., \& Lorne, C. (2015). Maplocal: Use of Smartphones for Crowdsourced Planning. Planning Practice \& Research, 30(3), 322-336.

33. Evans-Cowley, J. (2014). The Best Planning Apps for 2014. Retrieved from http://www.planetizen.com/node/66853

34. Martí, I. G., Rodríguez, L. E., Benedito, M., Trilles, S., Beltrán, A., Díaz, L., \& Huerta, J. (2012) Mobile Application for Noise Pollution Monitoring through Gamification Techniques. In D. Hutchison, T. Kanade, J. Kittler, J. M. Kleinberg, F. Mattern, J. C. Mitchell, . . M. Masuch (Eds.), Lecture Notes in Computer Science. Entertainment Computing - ICEC 2012 (pp. 562-571). Berlin, Heidelberg: Springer Berlin Heidelberg.

35. Thiel, S.-K., Lehner, U., Stürmer, T., \& Gospodarek, J. (2015). Insights from a m-participation prototype in the wild. In IEEE International Conference on Pervasive Computing and Communication workshops (pp. 166-171). Piscataway, NJ: IEEE.

36. Thiel, S.-K., Fröhlich, P., \& Sackl, A. (2016). Experiences from a Living Lab Trialling a Mobile Participation Platform. In M. Schrenk, V. V. Popovich, P. Zeile, P. Elisei, \& C. Beyer (Eds.), REAL CORP 2016. Proceedings of 21st international conference on Urban Planning, Regional Development and Information (pp. 263-272). Wien: CORP - Competence Center of Urban and Regional Planning.

37. Stembert, N., \& Mulder, I. J. (2013). Love your city!: An interactive platform empowering citizens to turn the public domain into a participatory domain. In International Conference Using ICT, Social Media and Mobile Technologies to Foster Self-Organisation in Urban and Neighbourhood Governance.

38. Thiel, S.-K. (2016). A Review of Introducing Game Elements to e-Participation. In Conference for EDemocracy and Open Government (CeDEM) (pp. 3-9).

39. Gordon, E., \& Baldwin-Philippi, J. (2014). Playful Civic Learning: Enabling Reflection and Lateral Trust in Game-based Public Participation. International Journal of Communication, 8, 759-786.

40. Fung, A. (2006). Varieties of Participation in Complex Governance. Public Administration Review 66

41. Renn, O., Webler, T., Rakel, H., Dienel, P., Johnson, B. (1993). Public participation in decision making: A three-step procedure. Policy Sciences 26, 189-214. 